\title{
Influence of Wavelength on Photo-Assisting Anodic Electrodeposition of Ceria Thin Films
}

\author{
Yang Yang ${ }^{1}$, Ze-gang Dong ${ }^{1}$, Zhao Zhang ${ }^{2, *}, Y u$ Chen $^{2}$, Yin-ye Yang ${ }^{1}$, Hai-jun Du ${ }^{3}$ \\ ${ }^{1}$ School of Materials Science and Engineering, Guizhou Minzu University, Guiyang 550025, P. R. \\ China \\ ${ }^{2}$ Department of Chemistry, Zhejiang University, Hangzhou 310027, P. R. China \\ ${ }^{3}$ School of Chemistry and Eco-Environmental Science, Guizhou Minzu University, Guiyang 550025, \\ P. R. China \\ *E-mail: eaglezzy@ zjuem.zju.edu.cn
}

doi: $10.20964 / 2017.03 .53$

Received: 31 July 2016 / Accepted: 19 January 2017 / Published: 12 February 2017

Cerium oxide films have been anodically deposited with photo-assisting onto 316L stainless steel in bath solution containing $0.05 \mathrm{M}$ cerium (III) nitrate, $0.1 \mathrm{M}$ ammonia acetate and $70 \%(\mathrm{~V} / \mathrm{V})$ ethanol. Three monochromatic photo wavelengths $(254 \mathrm{~nm}, 365 \mathrm{~nm}$ and $415 \mathrm{~nm})$ have been discussed. The electroplating behaviors and the structural of the films were investigated with $i$ - $t$ curves, ellipsometry, scanning electron microscopy, glancing angle X-ray diffraction, and Raman and X-ray photoelectron spectroscopy. Results show that, photo irradiation favors the anodic growth of ceria films. With shortening the incident photo wavelength from $415 \mathrm{~nm}$ to $254 \mathrm{~nm}$, the film thickness increase from $20.8 \mathrm{~nm}$ to $32.4 \mathrm{~nm}$ and the film crystallinity was enhanced. Moreover, shortening of the photo wavelength has a negligible effect on both the stoichiometry and the preferential occcbrientation growth of the deposits.

Keywords: Anodic electrodeposition; Photo irradiation; Ceria thin films

\section{$\underline{\text { FULL TEXT }}$}

(C) 2017 The Authors. Published by ESG (www.electrochemsci.org). This article is an open access article distributed under the terms and conditions of the Creative Commons Attribution license (http://creativecommons.org/licenses/by/4.0/). 